\title{
A LINGUAGEM FÍLMICA NA ESCOLA: A FANTASIA ACESSÍVEL PELA AUDIODESCRIÇÃO
}

\author{
MOVIE AT SCHOOL: THE FANTASY ACCESSIBLE BY THE \\ AUDIODESCRIPTION
}

DOI: http://dx.doi.org/10.5965/1984317815022019289

\author{
Maria Cecilia Tavares \\ Secretaria Municipal de educação da cidade do Rio de Janeiro \\ mariaceciliatavarestavares@gmail.com
}

\author{
Ana Beatriz Lago de Moraes \\ Secretaria Municipal de Educação da cidade do Rio de Janeiro \\ bialagomoraes@yahoo.com.br
}

\section{RESUMO}

O cinema é considerado como a $7^{\mathrm{a}}$ arte que fascina e absorve o espectador. Observa-se o uso crescente desta linguagem como ferramenta didática no cotidiano escolar. Ao aluno com deficiência visual deve ser garantido o direito de apreciar a linguagem fílmica, fato que requer a criação de mecanismos e estratégias que assegurem as condições de acessibilidade. A audiodescrição (AD) é um dos recursos de acessibilidade e é considerado também com um recurso pedagógico. O Centro de Referência em Educação Especial - Instituto Municipal Helena Antipoff, órgão da Secretaria Municipal de Ensino da Cidade do Rio de Janeiro, utiliza o recurso de audiodescrição em suas pesquisas aplicada na Rede de Ensino. Os estudos são desenvolvidos na Oficina de Audiodescrição. O objetivo deste artigo é relatar o estudo desenvolvido no ano de 2015 e 2016, resultado da elaboração de um roteiro de audiodescrição do filme Harry Potter e a Pedra Filosofal incluindo os elementos relevantes da linguagem cinematográfica. A pesquisa teve como objetivo obter dados acerca dos benefícios do referido roteiro para a formação de imagens, conceitos e fruição da pessoa com deficiência visual. Assim como, a relevância da audiodescrição dos elementos cinematográficos para a melhor percepção e compreensão da obra fílmica. Podemos concluir, através dos depoimentos, que a linguagem fílmica com áudio-descrição contribui na formação de conceitos referentes à realidade e a ficção.

Palavra-Chave: Acessibilidade Cultural. Audiodescrição. Escola. Cinema.

\section{ABSTRACT}

Cinema is considered as the 7th art that fascinates and absorbs the viewer. It is observed the increasing use of this language as a didactic tool in school. The student with visual impairment must be guaranteed the right to appreciate film language, a fact that requires the creation of mechanisms and strategies that ensure accessibility. The audio description is the pedagogical resource that the Reference Center for Special Education - Helena Antipoff Municipal Institute, an agency of the Municipal Department of Education of the City of Rio de Janeiro, uses in its researches applied in the Teaching Network. The studies are developed in the Audio Workshopdescription. The objective of this article is to report the study developed in the year 2015 and 2016, resulting from the elaboration of an audio-description script of the Harry Potter film and the Philosopher's Stone including the relevant elements of the cinematographic language. The aim of the research was to obtain data about the benefits of the mentioned script for the 
formation of images, concepts and enjoyment of the visually impaired person, as well as the relevance of the audio description of the cinematographic elements for the best enjoyment and understanding of the film work. We can conclude from the testimonies that film language contributes to the formation of concepts related to reality and fiction.

Keywords: Cultural Accessibility. Audiodescription. School; Movie.

\section{INTRODUÇÃO}

O filme é composto de imagens fotográficas projetadas em movimento. A linguagem fílmica é considerada como a $7^{\text {a }}$ arte que fascina e absorve o indivíduo, integrando outras linguagens artísticas como música, artes visuais e literatura. Sendo um meio de comunicação e expressão artística, esta linguagem é um meio de entretenimento que influencia no modo como enxergamos o mundo.

O acesso fácil às novas tecnologias visuais vem oportunizando a sociedade usufruir, cada vez mais, da linguagem cinematográfica, promovendo o acesso a novas informações, conhecimentos, reflexões e fruição artística. Diante disso, observa-se o uso crescente desta linguagem como ferramenta didática no cotidiano escolar.

Valer-se dessa linguagem na escola, agrega-se mais um elemento mediador social e cultural. A linguagem fílmica desenvolve o olhar crítico e reflexivo do aluno sobre os diferentes grupos, comportamentos e identidades sociais, reconhecendo-se e relacionando ao seu cotidiano.

Portanto, o aluno com deficiência visual na escola deve ter garantido a sua plena participação como apreciador e fruidor desta obra fascinante que é o filme.

Para que o aluno cego e com baixa visão possa ter garantido o seu direito como apreciador da linguagem fílmica deve- se criar mecanismos e estratégias que assegurem as condições de acessibilidade. No que se refere à inclusão cultural dos alunos com deficiência visual destacamos, para este estudo, o recurso de audiodescrição( $A D$ ) como ferramenta fundamental de acessibilidade.

$A$ audiodescrição (AD) é um recurso utilizado para tornar o teatro, o cinema, a $\mathrm{TV}$, bem como obras de artes visuais, meios acessíveis para cegos e pessoas com baixa visão. (MOTTA, 2010) 
Motta (2010) afirma que com o recurso de audiodescrição é possível conhecer os figurinos das personagens, as ações corporais dos atores, as suas expressões faciais e corpóreas, os cenários e ambientações utilizados nas peças teatrais, nos filmes e demais espetáculos de dança e música. Assim como, a descrição de obras de arte expostas nas galerias e museus.

A intenção de se descrever as imagens para uma pessoa cega ou com baixa visão, sempre existiu desde os mais remotos tempos. Informalmente e de forma precária, a pessoa com deficiência visual tentava se beneficiar ao máximo das informações orais que lhe eram fornecidas.

Os estudos e pesquisas produzidos sobre AD demonstram o avanço no uso da descrição das imagens em seus variados contextos. Há uma crescente apropriação dos recursos tecnológicos no mundo contemporâneo e também de políticas públicas relativas à inclusão cultural. .

No caso específico da educação, a escola é responsável por garantir ao aluno com deficiência visual a sua plena participação como apreciador de filmes quando utilizados como recurso pedagógico. Para tanto, é necessário o uso do recurso de $A D$ para que ele:

O Centro de Referência em Educação Especial - Instituto Municipal Helena Antipoff, órgão da Secretaria Municipal de Ensino do Rio de Janeiro entende a importância do recurso de $A D$ como um recurso pedagógico e para a inclusão cultural e social dos alunos com DV. Na Oficina de AD, as pesquisas se constituem, como um espaço de observação e experimentação da apreciação de obras artísticas utilizando este recurso de acessibilidade. Os resultados dos estudos são apresentados em cursos ministrados em formação continuada para os professores da Rede Municipal de Educação da cidade do Rio de Janeiro.

Neste artigo apresenta-se um relato do estudo desenvolvido no Centro de Referência em Educação Especial - Instituto Municipal Helena Antipoff, realizado pelas professoras de dança e de teatro responsáveis pela oficina de audiodescrição, com o resultado da elaboração de um roteiro de audiodescrição do filme Harry Potter e a 
Pedra Filosofal, incluindo os elementos relevantes da linguagem cinematográfica. A pesquisa teve como objetivo obter dados acerca dos benefícios do referido roteiro para a formação de imagens, conceitos e fruição da pessoa com deficiência visual, assim como, a relevância da audiodescrição dos elementos cinematográficos para a compreensão da obra fílmica.

\section{O CINEMA E O ALUNO COM DEFICIÊNCIA VISUAL}

A arte cinematográfica abrange diversas linguagens artísticas como a música, fotografia e as artes visuais. A áudio- descrição de filmes é uma técnica de tradução de imagens que consiste numa descrição seleta e objetiva do que seja importante para a compreensão do enredo e da imagem, procurando não interferir nas falas dos personagens, efeitos musicais e sonoros.( FARIAS , 2013 ).

O recurso de acessibilidade $A D$, possibilitará a pessoa com deficiência visual a desfrutar de um enredo com efeitos sonoros, somado a descrição das imagens e dos elementos da linguagem cinematográfica.

Entendemos como elementos da linguagem cinematográfica a linguagem da câmera, no que se refere à descrição do seu movimento ou de sua localização. Consideramos como elementos cinematográficos: os planos que descrevem a distância da câmera, em relação ao objeto/sujeito; os ângulos, que dizem respeito ao ângulo de visão pelo qual a imagem se revela e os movimentos da câmera que constituem a base técnica do plano em movimento. A linguagem cinematográfica revela a intenção do diretor. Como por exemplo, quando o diretor utiliza o close para dar destaque à expressão do personagem, uma parte do corpo ou utilizando o grande plano geral de uma floresta com intenção de mostrar a geografia física.

Esses elementos cinematográficos citados e outros que compõem a obra tem a finalidade de transmitir significados da cena, estabelecer a ambientação, gerar tensão ou outras emoções ao espectador. 
De acordo com Machado (2015), todos esses elementos conjugados contribuíram para a formação de conceitos e do simbólico no repertório imagético da pessoa cega e com baixa visão, gerando novas sensações para a maior fruição dessa arte.

Dessa forma, o acesso à linguagem cinematográfica por meio da audiodescrição, permitirá ao aluno com deficiência visual, desenvolver sua capacidade de elaborar imagens e adquirir novos conceitos .

Em relação à aquisição de conceitos pelas pessoas com deficiência visual, Warren (1994), encontrou pesquisas que concluem que a formação de imagens e conceitos da pessoa com deficiência visual se dá pela experiência tátil, auditiva e olfativa. Vygotsky (1998) comenta que a aquisição de conceitos é mediada por signos, particularmente, pela linguagem. Essas duas experiências se mostraram interrelacionadas com a linguagem verbal.

Desse modo, no caso da pessoa cega, a linguagem verbal é o principal canal de informação na aquisição de conceitos. Assim de acordo com Machado (2015), a linguagem representa a forma de descrições onde vai se formando uma rede de significados, relacionando-se e (re) elaborando-se novos conceitos.

Ormelezi (2000) afirma que é fundamental que a formação de conceitos e de imagens se dê utilizando a linguagem verbal, principalmente quanto aos conceitos pouco ou nada acessíveis onde não é possível vivenciar concretamente. Nas palavras de ORMELEZI (2000):

É importante proporcionar experiências que a palavra esteja ligada a uma vivência e que ambas sejam significativas para não traduzirem em experiências vazias. Que se criem estímulos especiais, porém não artificiais e descontextualizados. (ORMELEZI, 2000, pg. 207)

O filme com o recurso de audiodescrição oportuniza o aluno a adquirir novos conceitos, a ampliar suas possibilidades de percepção do mundo, das diversas expressões artísticas-culturais partindo de uma experiência prazerosa e 
contextualizada. A arte cinematográfica permite ao espectador penetrar na atmosfera do enredo, construindo imagens mentais.

Para que de fato ocorra à apreensão de todos esses elementos conjugados ao prazer de assistir a obra fílmica, o aluno precisa desfrutar, desde cedo, de uma educação visual para que possa estar inserido no contexto imagético presente no seu cotidiano. Como explica Machado.

Uma educação visual por meio da arte cinematográfica significa oferecer à pessoa cega novas possibilidades de apreensão das imagens para que ela adquira, a seu modo, a experiência do olhar e estabeleça com liberdade sua conexão com o mundo exterior. (MACHADO, 2015, pg. 39)

Assim, é fundamental que se vivencie desde cedo o acesso ao cinema com AD. A escola é o espaço propício para iniciar esta vivência e orientar as famílias. A escola precisa informar a família sobre a importância da criança usufruir da linguagem fílmica garantindo-lhe sua efetiva inclusão cultural.

\section{3. ÁUDIO-DESCRIÇÃO DE FILMES}

A audiodescrição de filmes está cada vez mais disponibilizada para as pessoas com deficiência visual.

Casado (2007) comenta que os elementos que devem ser audiodescritos se dividem em elementos visuais não verbais e visuais verbais. Entre os elementos visuais não verbais estão: Personagens (figurino, atributos físicos, expressões faciais, linguagem corporal, etnia e idade); Ambientação (elementos espaciais), elementos temporais (localização temporal dos personagens) e Ações. Como elementos visuais verbais citam-se os títulos, os créditos e as legendas.

Nos filmes é fundamental, além de descrever os elementos verbais e não verbais, considerar a descrição de elementos cinematográficos utilizados pelo diretor para melhor compressão da obra.

Os tipos de planos, como um dos elementos cinematográficos, descrevem a distância da câmera em relação ao objeto/sujeito. Como explica Barnwell (2013) varia 
de plano próximo (close-up) ao grande plano geral. Quanto mais longe o plano mais informações contextuais se ganha e quanto mais perto mais detalhes são percebidos. Os planos se encarregam de organizar as distintas possibilidades de distribuição do material no enquadre, Como por exemplo, o grande plano geral, quando mostra a imagem ampla como uma floresta; o plano detalhe quando mostra um detalhe da cena.

Outro elemento são os ângulos que dizem respeito ao ângulo de visão onde a imagem parece colocar os espectadores em uma determinada posição frente ao plano. Os tipos de planos são: o plano frontal; plongée, e o contra-plongée. No ângulo frontal a câmera é situada na altura normal dos olhos. No ângulo plongée o material é filmado de cima para baixo. Para Martin (2003), esse plano busca evidenciar a inferioridade, a vulnerabilidade e a insignificância. Já no contra-plongée o material é filmado de baixo para cima e geralmente é utilizado para impor um ar de superioridade, de triunfo, ao objeto ou lugar.

O movimento da câmera também faz parte da linguagem cinematográfica como o zoom -in ou zoom- out onde as lentes da câmera ajustam a distância, mas a câmera permanece imóvel. O zoom-in faz com que a imagem pareça maior, enquanto o zoomout faz a imagem parecer menor.

O diretor utiliza a linguagem cinematográfica para intensificar ou dar destaque a algum momento importante da cena. Por exemplo, um close no rosto do personagem para mostrar a sua expressão ou um plano detalhe em algum objeto que terá uma importância no enredo. Tudo isso compõe a obra com a intenção de transmitir o significado da cena, estabelecer a ambientação, gerar tensão ou diferentes emoções ao espectador. Assim, para que a pessoa com deficiência visual possa usufruir integralmente da obra precisa ter acesso aos elementos cinematográficos que compõem a cena, conhecendo a intenção do diretor. A audiodescrição é um recurso de acessibilidade que leva o espectador a apropriar-se da obra artística. Assim, acreditamos que os elementos cinematográficos devam ser audiodescritos. O roteiro de audiodescrição deverá ser elaborado primando a seleção dos elementos cinematográficos que são importantes para a compreensão e fruição da cena. 
A distância e o posicionamento da imagem influem muito na dramaticidade do ocorrido, seja para um beijo em uma telenovela, as lágrimas de uma criança em um telejornal ou o discurso de um político em sua campanha eleitoral. Esta capacidade de aumentar ou diminuir a dramaticidade da cena monta um dos paradigmas mais elementares da linguagem cinematográfica. (MACHADO, 2015, pg.78)

Outro elemento fundamental nas produções audiovisuais é a trilha sonora. É importante que o roteiro de audiodescrição preserve a trilha sonora quando for relevante para a cena, não sobrepondo a esta a voz do audiodescritor. A música, em muitos momentos, fornece indícios primordiais para a compreensão e clima da cena apresentada levando não só o vidente, mas também a pessoa com deficiência visual a envolver-se nesta atmosfera. Nos filmes do gênero fantasia, como o de Harry Potter, filme elencado neste estudo, utiliza-se muito a trilha sonora para transmitir suspense.

O cuidado e seletividade adequada para a escolha do que será preservado ou não da trilha sonora, a tradução em palavras das imagens e dos aspectos da linguagem cinematográfica a serem utilizados no roteiro de audiodescrição torna-se condição sine qua non para levar o sujeito com deficiência visual a usufruir integralmente da obra fílmica.

O empobrecimento de experiências imagéticas na vida das pessoas com deficiência visual dificulta a formação de conceitos referentes ao que não existe na realidade, o que não pode ser sentido através do tato ou conhecido por outros sentidos. Assim, tem-se como pressuposto da pesquisa que o filme do gênero fantasia com audiodescrição irá proporcionar experiências que favorecem a formação de conceitos sobre objetos ilusórios e ações mágicas.

A seguir iremos expor a metodologia utilizada para elaborar o roteiro de audiodescrição do filme Harry Potter e Pedra Filosofal, incluindo os elementos relevantes da linguagem cinematográfica. O estudo permitiu levantar dados acerca dos benefícios do referido roteiro para a formação de imagens, conceitos e fruição da pessoa com deficiência visual. 


\section{PROCEDIMENTO METODOLÓGICO}

O corpus do estudo foi composto de alunos jovens com deficiência visual da Rede Municipal de Educação da cidade do Rio de Janeiro, sendo seis alunos cegos e três com baixa visão na faixa etária de 14 a 21 anos. Os alunos estão incluídos em uma turma no PEJA- programa de jovens adultos. Os alunos frequentam a Oficina de Audiodescrição do Instituto Municipal Helena Antipoff, órgão da Secretaria Municipal de Ensino da Cidade do Rio de Janeiro, onde desenvolveu o referido estudo.

Os alunos foram atendidos na oficina de audiodescrição do referido Instituto, que se constituiu como um espaço de observação e experimentação da apreciação de diversas obras artísticas com audiodescrição. Assim, como a elaboração de propostas pedagógicas sobre a audiodescrição para serem aplicadas no cotidiano escolar.

Outras pesquisas vêm sendo desenvolvidas no espaço da Oficina de Audiodescrição. Os estudos realizados são apresentados em cursos ministrados em formação continuada para os professores da Rede Municipal de Educação da cidade do Rio de Janeiro.

O estudo desenvolvido no ano de 2016 e apresentado neste documento é um roteiro de audiodescrição do filme Harry Potter e a Pedra Filosofal, incluindo os elementos relevantes da linguagem cinematográfica e levantando dados acerca dos benefícios do referido roteiro na formação de imagens e conceitos da pessoa com deficiência visual.

\subsection{HARRY POTTER - A FANTASIA FÍLMICA}

A escolha do filme Harry Potter e a Pedra Filosofal para este estudo se deu pelo fato de as alunas cegas, participantes da oficina, desconhecerem o personagem Harry Potter. Os alunos com baixa visão conheciam o personagem, mas nunca tinham tido a oportunidade de assistirem a um filme. Ao ser esclarecido que o filme é do gênero fantasia e que o mesmo se passava numa escola de bruxos, reagiram com espanto e medo. 
Ao nos defrontamos com o desconhecimento e com os preconceitos incutidos nesses jovens estudantes, percebemos a relevância de reconstruir e ampliar os conceitos referentes à fantasia, ficção, magia e criação artística a partir do recurso da linguagem fílmica.

O filme Harry Potter é reconhecido como um filme do gênero fantasia. O termo fantasia refere-se ao que é criado pela imaginação, o que não existe na realidade. Fantasia é um gênero que usa a magia e outras formas sobrenaturais como elemento principal do enredo, da temática e / ou da configuração. Os acontecimentos e ações são explicados por uma intervenção divina, mágica, ou de outras forças sobrenaturais.

\subsection{ELABORAÇÃO DO ROTEIRO DE AUDIODESCRIÇÃO - FILME HARRY POTTER E A PEDRA FILOSOFAL}

O roteiro incluiu a descrição de alguns elementos da linguagem cinematográfica. Esses elementos foram escolhidos por serem fundamentais para a compreensão e formação de imagens e conceitos da cena.

Os elementos áudio- descritos foram divididos em:

- Quanto aos planos: Grande plano geral, plano geral e close-up,

- Quanto aos ângulos: Plongée e contra plongée.

\subsection{A ESTRATÉGIA REALIZADA NO ESTUDO}

O grupo de alunos participou de aulas semanais com duração de 3 horas. As aulas ocorreram de fevereiro a novembro de 2016. No primeiro momento eram oferecidas atividades práticas com o objetivo de desenvolver os conceitos relacionados à linguagem cinematográfica. Posteriormente, era exibido um trecho do filme. $O$ filme foi dividido em capítulos.

As atividades práticas foram propostas para a compreensão dos elementos da linguagem cinematográfica. Para a noção do plano close-up, por exemplo, foram utilizadas molduras de madeira onde os alunos através do tato identificavam o seu rosto rente à moldura, dando a ideia deste plano. Numa cena do filme mostra o close- 
up da cicatriz de Harry Potter. Para que os alunos compreendessem este elemento maquiamos a cicatriz em alto relevo na testa dos alunos, Depois foram tiradas fotos em close da testa. As fotos impressas foram transformadas em foto tátil, onde os cabelos, o contorno do rosto, os sinais faciais e as partes do rosto foram reproduzidos em alto relevo para que eles compreendessem o que a imagem close-up significa. Ampliamos gradativamente o enquadramento utilizando outros recursos e estratégias levando-os a ideia dos diversos planos nas cenas, até chegar a compressão do grande plano geral.

Quanto à compreensão dos diversos ângulos foi inicialmente proposto atividades com o objetivo que os alunos compreendessem o conceito de localização da câmera em relação à imagem a ser filmada. Foi vivenciado o posicionamento da câmera de frente, em cima ou em baixo em relação à imagem a ser capturada. Atividades em dupla foram sugeridas onde um aluno se posicionava com a câmera e o outro aluno seria filmado. Por exemplo: O aluno que seria filmado sentado no chão e o outro com a câmera de pé, percebendo tatilmente e sonoramente a posição do sujeito sentado no chão. Dando a noção da filmagem de cima para baixo. Assim como o aluno deitado no chão com a câmera percebe o colega a ser filmado, de baixo para cima.

A pesquisa de caráter qualitativo foi constituída por materiais orais utilizando questionário semiestruturado aplicado após as aulas. Levantaram-se dados acerca dos conceitos sobre magias e os objetos irreais encontrados nas cenas, assim como a relevância da audiodescrição dos elementos cinematográficas para a melhor fruição e compreensão da obra fílmica.

\section{DISCUSSÃO E RESULTADOS:}

A discussão e o resultado obtidos da audiodescrição a partir do estudo foram estruturados em 11 cenas organizadas num protocolo que começa com a escolha do elemento cinematográfico, audiodescrição da cena, seguido do detalhamento das cenas, comentários dos alunos e reflexão dos resultados obtidos. Para compreensão de cada estudo são apresentados os elementos cinematográficos: close, grande plano 
geral, plongée e contra - plongée. Os quadros 1, 2 e 3 sistematizam a proposta com destaque ao elemento Close e grande plano geral.

Quadro 1 - Protocolo de audiodescrição Filme Harry Potter - Cenas 1 e 2

\section{Elemento cinematográfico: Close}

\section{Audiodescrição da Cena:}

Cena 1

- 03:50/ 04:03 - Close no bebê. Do lado direito da testa, cicatriz em forma de raio.

Cena 2 -

(Harry)- Ai!

43: 59/44: - Harry coloca a mão na cicatriz

(Ronny) $\mathrm{O}$ que foi?

44:05/44:06 - Close no professor sério. Close em Harry. Testa franzida

\section{Detalhamento da Cena:}

A audiodescrição acima citada descreve o close da cicatriz na testa de Harry Potter. Esta cicatriz tem grande importância no filme, pois é a marca deixada pelo assassino dos pais de Harry. Assim, o diretor evidenciou a testa do personagem utilizando o close em várias cenas. Na cena 2, Harry coloca a mão na cicatriz sentindo dor. A expressão de dor na cicatriz é fundamental no enredo, assim como o olhar do professor nesta cena. O Diretor demonstra, por meio do uso do close, a importância da sensibilidade do personagem relacionada à cicatriz.

Comentário(s) do(s) aluno(s):

A 2- Acho que isso é importante no filme. Quando vamos saber quem fez a cicatriz?

A3 - Gostei de fazer em mim a cicatriz do raio do Harry Potter

A1- Aparece igual a nossa foto. Aparece grande.

\section{Reflexão dos resultados:}

Nestas duas cenas, a descrição deste elemento cinematográfico, close, para o aluno com deficiência visual deixou claro que a marca na testa do personagem era importante para o enredo do filme. Descrever o close na testa de Harry despertou nos alunos a curiosidade de descobrir quem provocou aquela cicatriz.

O diretor ao priorizar a dramaticidade do personagem lança mão do plano close, destacando, o que pretende mostrar. É importante que o espectador com deficiência visual saiba sobre a escolha do diretor em intensificar a expressividade do personagem naquele momento cênico (quadro 2).

Quadro 2 - Protocolo de audiodescrição Filme Harry Porter - Cena 3 


\section{Elemento cinematográfico: Close}

\section{Audiodescrição da cena:}

Cena 3-

(Hagrid) Ninguém sobrevivia se ele decidisse matar. Exceto você. Menino que Sobreviveu.

30:57/30:58 - Close em Harry sério.

\section{Detalhamento da Cena:}

A cena audiodescrita acima revela o momento que Hagrid conta a Harry sobre Voldemort, o assassino de seus pais. $O$ diretor utilizou o close para evidenciar a expressividade do personagem neste momento, dando prioridade em concentrar o quadro a expressão de Harry.

\section{Comentário(s) do(s) aluno(s)}

A5 - Fiquei com medo nesse momento.

A2 - Achava que close era armário. Agora entendi que é para mostrar perto e mostrar só o rosto.

A1: Achamos que falando do close a gente entende que é importante.

A4: Eu fico mais atenta, presto mais atenção porque quando falam de um close ou detalhe sei que vai acontecer alguma coisa, sei que é importante.

A3- O close mostra de perto. É grande. Mostra os sentimentos do personagem.

\section{Reflexão dos resultados:}

Observamos que as atividades práticas oferecidas aos alunos sobre o termo close clarificou e ampliou o conceito da palavra, assim como, o repertório imagético relacionado às expressões faciais dos personagens.

\section{Quadro 3 - Protocolo de audiodescrição Filme Harry Potter - Cenas de 4 a 7}

\section{Elemento cinematográfico: Grande plano geral.}




\section{Audiodescrição da cena:}

Cena 4

12:16/ 12:23 - Grande plano geral, mar agitado ,temporal, raios, trovões, ilha pequena casa.

Cena 5

18:24/ 18:26 - Grande plano geral de Londres

Cena 6

34:04/34:13 - Grande plano geral trem em movimento, campo verde, árvores, animais pastando, céu azul, nuvens brancas. Fumaça branca da locomotiva.

Cena 7

38:40/38:48 - Grande Plano geral - barcos, céu escuro, névoa, montanhas, lua encoberta por nuvens, grande castelo iluminado.

\section{Detalhamento da Cena:}

Na cena 4, é audiodescrito o grande plano geral do mar mostrando a amplitude do ambiente natural e o isolamento da nova moradia da família de Harry. Na cena 5 mostra o grande plano geral da cidade de Londres, situando o espectador no novo ambiente geográfico da cena. Na cena 7 é utilizado o grande plano geral na chegada dos alunos a escola de Hogwarts visando destacar o ambiente natural em que se localiza o castelo de Hogwarts, intensificando a grandiosidade da escola .

\section{Comentário(s) do(s) aluno(s)}

Nos depoimentos abaixo descritos percebemos que compreenderam que a cena mostrava um grande ambiente.

A5- A quadra da escola é grande. Tem árvores e tem o prédio do refeitório. Tem muitos alunos.

A6- A praia da casa é bem grande, caminhamos bastante na areia.

A4- A escola dos bruxos é em um castelo grande.

A3- Na minha escola não tem um refeitório como a escola do Harry.

\section{Reflexão dos resultados:}

Para que os alunos compreendessem os diversos ambientes no filme foi essencial descrever o grande plano geral para indicar as mudanças de ambientes geográficos das cenas. O elemento grande plano, para o entendimento e a percepção da grandiosidade de outros espaços cênicos como o interior da escola, o refeitório e outros.

Para dar aos alunos a noção do que venha a ser um grande plano geral e um plano geral relacionamos aos ambientes de seu cotidiano. Os prédios escolares, moradias e seus entornos, assim como, as praias conhecidas por eles.

Quanto aos ângulos não foi utilizada a nomenclatura técnica plongée e contraplongée. Foi empregado o termo: a câmera focaliza de baixo para cima ou de cima para baixo para ficar mais acessível aos alunos. 
Elemento cinematográfico: Plongée- ( câmera focaliza de cima para baixo )

\section{Audiodescrição da cena:}

Cena 8

58:48/ 58:51 - Câmera focaliza de cima para baixo os colegas no campo . Olham Harry parado no ar com a bola.

Elemento cinematográfico: contra-plongée (câmera focaliza de baixo para cima)

\section{Audiodescrição da cena:}

Cena 9

21:54/21:56 - Câmera focaliza de baixo para cima grande prédio do banco.

Cena 10

48:17/ 48:24 - Câmera focaliza de baixo para cima muitas escadas. Elas se movimentam.

\section{Cena 11}

01:09:58/01:10:04- Hermione vê pés gigantes. Olha de baixo para cima monstro gigante com um porrete na mão

\section{Detalhamento da Cena:}

A cena 8 mostra a altura e distância em que Harry está dos colegas .Na cena 9 foi utilizado o ângulo contra plongée com a intenção clara de filmar o olhar do personagem acompanhando a altura do prédio do banco, demonstrando a imensidão do prédio onde Harry irá entrar. Assim como, na cena 10 que aparece as escadas se movimentando no grande interior do castelo, revelando o triunfo da escola de Hogwarts. Na cena 11 a câmera revela o olhar da personagem desvendando aos poucos, de baixo para cima, a altura do gigante.

\section{Comentário(s) do(s) aluno(s)}

A 5- Ah, o banco é grande? Acho que Harry ficou com medo de entrar no banco.

A 8- A escola tem muitas escadas.

A 3 - Jogo na vassoura não existe. Como Harry voou alto.

A 6- Então o homem que filma ficou no chão e as vassouras no ar 
Quadro 5- Protocolo de audiodescrição Filme Harry Potter- Magia e Objetos Irreais

Ao final do filme pedimos que as alunas citassem magias e objetos irreais presentes no filme. Alguns depoimentos:

\section{MAGIA}

A1 - A varinha apontou e levantou a pena

A2- Passou pela parede quando foram pegar o trem

A3- Aparece um rabo no primo Duda

A7 - Hagrid com o guarda-chuva acende a lareira.

A1- O gato vira a professora

A 4- Hermione com a varinha conserta os óculos de Harry

\section{OBJETOS IRREAIS}

A7- Parede que abre

A 3- Chapéu que fala

A 4 -Escadas que andam

A 1- Varinha mágica

A 2- Moto que voa

A5- Vassoura que voa

Reflexão dos resultados:

Os alunos citaram magias e objetos irreais diferenciando ações de objetos. Nos depoimentos constatouse que relacionam os objetos com suas funções reais, conhecidas por eles, e irreais criadas no filme.

Diante dos depoimentos constata-se que a linguagem cinematográfica audiodescrita nas cenas contribuiu para a compreensão de conceitos do repertório imagético, assim como, as intenções da direção.

\section{CONSIDERAÇÕES FINAIS}

Os elementos cinematográficos despertam e acrescentam emoções que contribuem esteticamente para a compreensão da obra. Observamos que por meio de 
um roteiro de audiodescrição que valoriza os elementos cinematográficos, a pessoa com deficiência visual usufrui dessas emoções tendo acesso, de fato, a essa linguagem artística. Diante dos depoimentos percebemos que os alunos demonstraram satisfação em assistir ao filme e relataram que entenderam, através da audiodescrição, a intenção do diretor nas cenas. Constatamos, a partir dos dados obtidos no estudo, que os alunos adquiriram uma percepção nova sobre a arte cinematográfica.

Concluímos que a linguagem fílmica motivou e contribui na formação de conceitos referentes à realidade e a ficção. Na sala de aula, o professor ao explorar diferentes conceitos através da obra fílmica, beneficiará também o aluno sem deficiência. Com a utilização da $A D$ no contexto escolar, os alunos com e sem deficiência visual podem reconhecer suas possibilidades e ter acesso a linguagem fílmica em igualdade de condição. Acreditamos que seja fundamental o trabalho pedagógico visando uma educação visual estética voltada para as linguagens artísticas.

Entendemos que é urgente a escola se apropriar deste conteúdo e uso deste recurso de acessibilidade visando proporcionar, desde cedo, que o aluno com deficiência visual vivencie a linguagem fílmica com audiodescrição adquirindo uma familiaridade com o recurso. A escola é um espaço para despertar o gosto de assistir filmes com audiodescrição. Cabe a ela, como um espaço de formação, incentivar as famílias a frequentar os espaços culturais formando cidadãos autônomos em busca de uma verdadeira inclusão cultural.

Finalmente, a estratégia utilizada comprova o pressuposto da pesquisa que 0 filme do gênero fantasia com audiodescrição contribuiu significativamente na formação de conceitos sobre objetos ilusórios e ações mágicas, por parte dos estudantes cegos e com baixa visão.

\section{REFERÊNCIAS:}

BARNWELL, J. Fundamentos de produção cinematográfica - Porto Alegre: Bookman, 2013. 


\section{EDUCAÇÃO, \\ ARTE'S E INCLUSÃO}

CASADO, A.B. La Audiodescripción: Apuntes sobre el estado de la cuestión y las perspectivas de investigación. tradtern,n13,p.151-169,2007.

FARIAS, S. R. R. Audiodescrição e a poética da linguagem cinematográfica: um estudo de caso do filme Atrás das Nuvens. Tese de doutorado, Faculdade de Educação, Universidade Federal da Bahia, Salvador. 2013.

MACHADO, I. P. R. A parte invisível do olhar -audiodescrição no cinema : a constituição das imagens por meio das palavras - uma possibilidade de educação visual para a pessoa com deficiência visual no cinema /Campinas, SP . 2015.

MARTIN, M. A linguagem cinematográfica. São Paulo: Brasiliense, 2003.

MOTTA, L. M. V.M. e ROMEU F.P. (Orgs). Audiodescrição transformando Imagens em Palavras. São Paulo: Secretaria dos Direitos da Pessoa com Deficiência do Estado de São Paulo, 2010.

ORMELEZI, E. M. Os caminhos da aquisição do conhecimento e a cegueira: do universo do corpo ao universo simbólico. Dissertação de mestrado, Faculdade de Educação, Universidade de São Paulo, São Paulo. 2000.

VYGOTSKY. L.S. Pensamento e Linguagem. Rio de Janeiro: Martins Fontes, 1998. WARREN, D.H. Blindness and Children: An individual differences approach. USA: Cambridge University Press, 1994.

Recebido em 20 de setembro de 2017 Aprovado em 17 de março de 2020 